E-Note

\title{
Foraging Rates of Larval Dragonfly Colonists Are Positively Related to Habitat Isolation: Results from a Landscape-Level Experiment
}

\author{
Shannon J. McCauley, ${ }^{1,2, *}$ Tomas Brodin, ${ }^{3,4}$ and John Hammond ${ }^{5,6}$ \\ 1. Center for Population Biology, Department of Entomology, University of California, Davis, California 95616; 2. Department of \\ Ecology and Evolutionary Biology, University of Toronto, 25 Willcocks Street, Toronto, Ontario M5S 3B2, Canada; 3. Department of \\ Ecology and Environmental Science, Umeå University, S-90187 Umeå, Sweden; 4. Department of Environmental Science and Policy, \\ University of California, Davis, California 95616; 5. Department of Environmental Science and Policy, Ecology Graduate Group, \\ University of California, Davis, California 95616; 6. Department of Biological Sciences, University of Pittsburgh, Pittsburgh, \\ Pennsylvania 15260
}

Submitted March 18, 2009; Accepted August 12, 2009; Electronically published January 28, 2010

\begin{abstract}
There is increasing evidence of intraspecific variation in dispersal behavior. Individual differences in dispersal behavior may be correlated with other traits that determine the impact individuals have on patches they colonize. We established habitat patches-artificial pools-across a landscape, and these pools were naturally colonized by dragonfly larvae. Larvae were collected from pools at different levels of isolation and held under common lab conditions for 5 months. We then compared larval foraging rates. Foraging rate was positively related to habitat isolation, and colonists from the most isolated artificial pools had significantly higher foraging rates than individuals from the least isolated pools. Our results indicate that spatial patterns in colonist behavior can develop across a landscape independent of species-level dispersal limitation. This finding suggests that studies of community structure across space should include an assessment of the distribution of phenotypes as well as species-level dispersal limitation patterns.
\end{abstract}

Keywords: patch isolation, foraging rate, predation, colonization.

\section{Introduction}

Dispersal links populations and communities that occur in spatially subdivided habitat patches, affecting population persistence and community composition (Hanski 1999; Holyoak et al. 2005). A large body of research has examined how the physical structure of habitats - their proximity, size, and surrounding matrix conditions-affect the extent to which individuals disperse between patches and the consequent level of population and community connectivity (Hanski 1999; Holyoak et al. 2005; Crooks and Sanjayan 2006). However, the rates of move-

* Corresponding author; e-mail: shannon.mccauley@utoronto.ca. Am. Nat. 2010. Vol. 175, pp. E000-E000. (C) 2010 by The University of Chicago. 0003-0147/2010/17503-51158\$15.00. All rights reserved. DOI: $10.1086 / 650444$ ment between patches are only part of what determines the impact of those movements on patches. Considerable evidence suggests that individuals vary in their dispersal behavior, including both the decision to disperse and the distance they move during dispersal (Ims and Hjermann 2001; Conrad et al. 2002; Massot et al. 2002; Barbraud et al. 2003; Dingemanse et al. 2003; Cote and Clobert 2007). Phenotype-dependent dispersal has the potential to modify the impact that dispersers have on the patches they colonize (Duckworth and Badyaev 2007; Benard and McCauley 2008). For example, if fecundity and dispersal capacity are inversely related (e.g., Hill et al. 1999a), the extent to which dispersers affect the demography of the receiving patch they colonize will be less than predicted based on the mean population fecundity. Similarly, the impact of immigrants as predators or competitors in the community of the receiving patch will depend on traits that may be associated with differences in dispersal behavior. The directionality of this relationship (i.e., positive or negative) may be both system and context dependent (see table 1 in Clobert et al. 2009). Therefore, determining not only rates of dispersal but also whether the traits of new colonists differ across levels of habitat isolation is critical for understanding the full impact of dispersal and colonization on populations and communities.

Behavioral differences between individuals that have recently colonized habitats that differ in their level of spatial isolation would indicate that the impact of immigrants on a patch varies across space and cannot be estimated solely on the basis of the average behavior of colonists across all distances from source populations. We addressed this issue in dragonfly larvae, using individuals collected from an array of identical experimental pools distributed across a natural landscape. Larvae were subsequently held in com- 
mon lab conditions for much of their development before we examined foraging rates. This design allowed us to isolate the effects of habitat isolation from effects of habitat condition and recent experience. Dragonfly larvae are voracious predators and are often top predators in ponds when fish are absent (McPeek 1990). Consequently, their impact as predators on lower trophic levels and their impact as competitors with other predatory species are likely to be two of their dominant effects on members of the community in the receiving patch at which they arrive. In this study we addressed two related questions: (1) is there a relationship between habitat isolation and foraging rate in dragonfly larvae? and (2) if larvae from different levels of isolation differ in foraging rate, is the relationship between patch isolation and colonist foraging rate positive or negative?

\section{Material and Methods \\ Colonization Experiment}

The colonization experiment was carried out at the Wantrup Wildlife Sanctuary (WWS), Napa County, California $\left(38^{\circ} 35^{\prime} 44^{\prime \prime} \mathrm{N}, 122^{\circ} 22^{\prime} 10^{\prime \prime} \mathrm{W}\right)$. We established three sites, levels $1-3$, that differed in their level of isolation from source habitats (fig. 1). The layout of the reserve, which is relatively narrow but provides a gradient of isolation from aquatic habitats along its longer axis, constrained us to these three levels rather than spreading out the levels in multiple directions away from the central set of ponds. Isolation of each site was characterized using Hanski's index of connectivity (1999), which integrates the potential contribution of multiple sites to the colonized site. Connectivity for each site was calculated using this metric based on the distance of the site to each of five ponds on the WWS and the circumference of each pond (details on spatial context and connectivity calculations in table A1). Circumference was used rather than pond area because dragonfly populations are concentrated in the pond littoral zone. We assumed a mean dispersal distance of $1 \mathrm{~km}$, but the rank order of site isolation is not sensitive to this parameter up to a distance of $10 \mathrm{~km}$ in this case (Hanski 1999).

Six 0.9-m-diameter children's wading pools were placed at each site, and each was filled with approximately $75 \mathrm{~L}$ of water from a well. Water levels in the artificial pools were maintained by adding water from the same source each week or as needed. Each pool was stocked with several elements to support insect colonists. These included $2 \mathrm{~m}$ of unbraided rope that provided structural complexity in the water, six dried cattail stems to provide a substrate for oviposition by endophytic invertebrates, a standard inoculum of Daphnia sp. to provide resources for colonists,

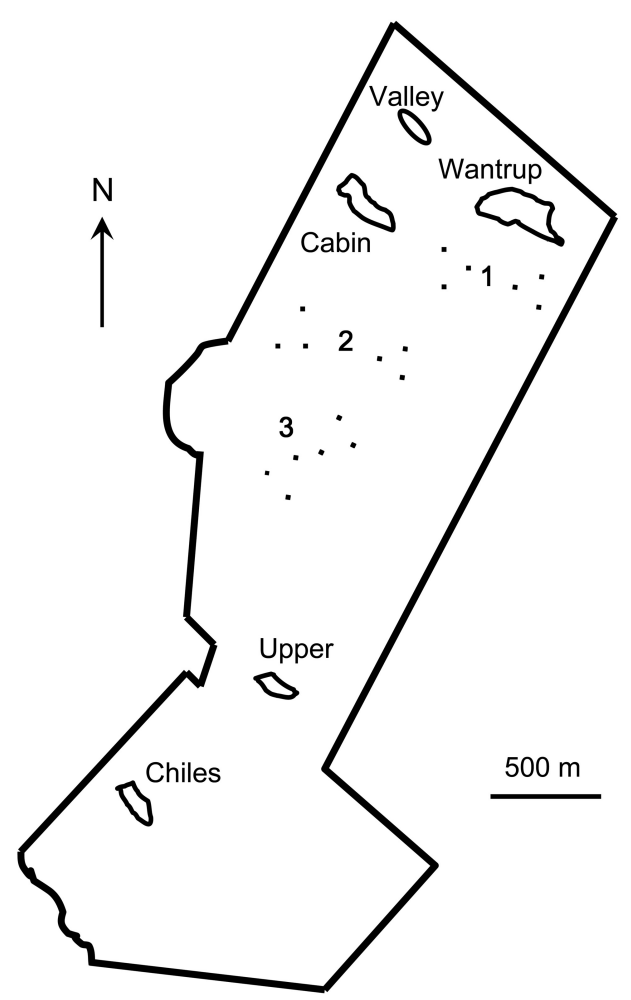

Figure 1: Map of study location (Wantrup Wildlife Sanctuary, Pope Valley, Napa County, California). Numbers indicate the position of each level of experimental pools. Dots indicate approximate experimental pool placement (note that pools are not to scale). Potential source environments are labeled by pond or lake name.

two pellets of rabbit chow to provide nutrients for algal growth, and a long stick that projected from the pool to provide a perch for visiting dragonflies. Pools were fitted with a rectangle of hard plastic that covered $\sim 25 \%$ of the water surface to provide shade and decrease water temperatures. Pools were established between May 18 and 23, 2007 , and monitored throughout the summer. Records of maximum and minimum tank temperatures were made in two randomly selected tanks at each level in two periods over the course of more than a week (details in appendix). Larval dragonflies in the genus Libellula were collected for this study on September 7, 2007, and brought back to the lab at the Aquatic Biology and Environmental Science facility on the campus of the University of California, Davis.

Tanks were also sampled for other invertebrates including potentially important prey species by sweeping a fine-screened net though the water column in a standardized way $(4 \times 0.75-\mathrm{m}$ sweeps $)$. Invertebrates collected using this method were preserved in $70 \% \mathrm{EtOH}$ and subsequently counted and identified to family or genus using 
a dissecting scope and a standard taxonomic key (Merritt and Cummins 1996).

\section{Behavioral Trials}

We characterized initial larval body size using size classes of body length $(1=0-0.5 \mathrm{~cm}, 2=0.5-1.0 \mathrm{~cm}, 3=$ $1.0-1.5 \mathrm{~cm}$ ) and then placed larvae individually in plastic cups filled with $\sim 500 \mathrm{~mL}$ of well water. Cups were systematically arranged in larger plastic bins set on shelving units within the lab. Cups were arranged to ensure that pools and levels were thoroughly mixed across the lab space, that each bin held larvae from each pool-level combination, and that cup position within bins was randomized. Larvae were held in the lab at $22^{\circ} \mathrm{C}$ under a 14L : 10D photoperiod and fed 20-30 Daphnia or 2-4 Tubifex every other day until 5 days before their use in behavioral trials. The most common species colonizing the pools was Libellula saturata, and we restricted our analyses to individuals of this species.

Five feeding trials were conducted in spring 2008, after larvae had been held under common lab conditions for at least 5 months. Each trial involved between 15 and 30 Libellula larvae, adding up to a total of 97 larvae of the focal species. Larvae were placed individually in waterfilled plastic tanks $(25 \mathrm{~cm} \times 15 \mathrm{~cm} \times 8 \mathrm{~cm})$ filled with 1.2 $\mathrm{L}$ aged well water containing 20 Daphnia. Larvae were allowed to feed for 24 hours and then removed. After larvae were removed we counted the number of surviving Daphnia in each tank.

After trials were completed, larvae were preserved in $70 \% \mathrm{EtOH}$ and identified to species under a dissecting scope using standard taxonomic keys (Needham et al. 2000). Head width was measured using digital calipers (to $0.01 \mathrm{~mm})$.

\section{Data Analysis}

Water temperatures of artificial pools at different levels were compared using a MANOVA with maximum and minimum temperatures as the response variables and level and date as the explanatory variables. A logistic regression was used to compare the size classes of larvae collected from pools at different levels with pool nested within level. We used ANOVAs to compare the abundance of prey taxa in pools colonized by L. saturata at different levels. Abundance was used as a measure of prey availability (appendix). One ANOVA compared the abundance of all potential prey taxa in the pools, including mayflies, damselflies, mosquito larvae, and chironomid larvae. The second compared only the abundance of mosquito larvae and chironomids, groups that were expected to be the most important prey for dragonfly larvae in these pools. To meet assumptions of normality, abundances were square root transformed.

Dry mass of each individual $L$. saturata was estimated based on head width using work by Benke et al. (1999, p. 399), which provides an equation for converting head width to dry mass for Libellula spp. Individual massspecific feeding rates were calculated (number of Daphnia consumed/estimated dry mass [mg]), and an average feeding rate per pool was generated. One individual outlier was removed within one of the pools. The data fit the assumptions of normality and equality of variances. An ANOVA was then used to test for level differences followed by least squared mean Tukey test to examine level differences. Analyses were conducted in SPSS 16.0.

\section{Results \\ Colonization Experiment}

Water temperature was not affected by level ( $T_{\max }$ : $\left.F_{3,15}=0.71, P=.57 ; T_{\min }: F_{3,15}=1.72, P=.24\right)$ or date $\left(T_{\max }: F_{1,15}=0.80, P=.397 ; T_{\min }: F_{1,15}=0.985, P=\right.$ .35) nor was there a significant interaction between level and date $\left(T_{\max }: F_{2,15}=0.267, P=.772 ; T_{\min }: F_{2,15}=\right.$ $0.382, P=.694)$. Sites differed in their level of isolation. Hanski's (1999) connectivity metric (Si), an inverse of isolation, varied across levels; pools at level 1 were most connected $(\mathrm{Si}=780)$, level 2 were intermediate $(\mathrm{Si}=$ $730)$, and pools at level 3 were most isolated ( $\mathrm{Si}=675$ ). Libellula larvae colonized artificial pools at all levels of habitat isolation. However, not all pools were colonized, and some pools were lost to the study because of damage that caused leaks. Consequently, larvae were collected from $3-5$ tanks per level (level $1=3$, level $2=5$, and level $3=3$ ). Multiple oviposition events were observed, and females were not observed moving between pools. While it remains possible that this movement occurred, decreasing the independence of these replicates, we have no evidence to suggest that this was an issue. Therefore, pools were used as the unit of replication. Larval body sizes did not differ between pools at different levels (log ratio $\chi^{2}=2.37, \mathrm{df}=2, P=.31$ ) at the time of collection. Prey abundances in the artificial pools did not differ between levels (all prey: $F_{2,10}=1.59, P=.26$; mosquitoes and chironomids: $F_{2,10}=2.57, P=.14$; table A2).

\section{Behavioral Trials}

Larvae from the three levels differed in their foraging rates $\left(F_{2,8}=7.03, P=.02\right)$. Larvae collected from the artificial pools closest to the source had significantly lower foraging rates than larvae collected from the most isolated pools (Tukey's post hoc, $P=.02$; fig. 2). Foraging rates of larvae 


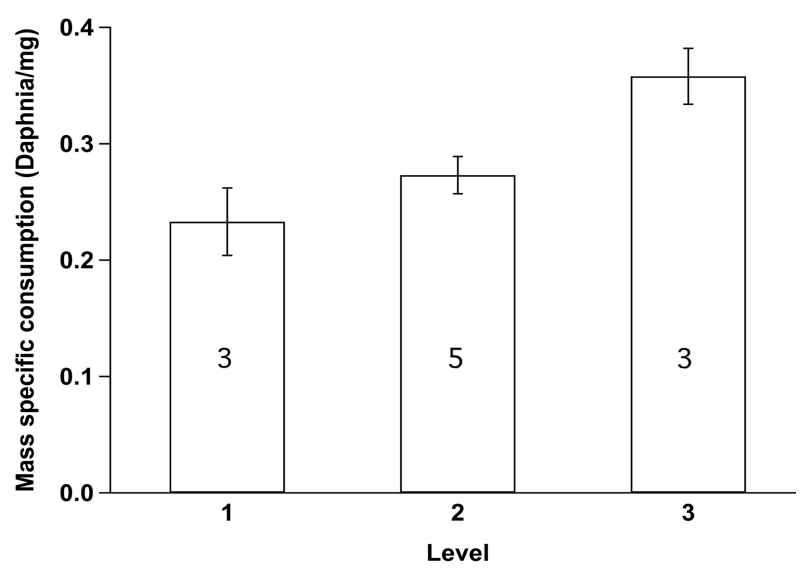

Figure 2: Mass-specific foraging (number of Daphnia consumed per mg) by larvae from each level of pool isolation $(1=$ least isolated, $2=$ intermediate, $3=$ most isolated). Bars represent mean $\pm 1 \mathrm{SE}$. Number of pools per level are listed inside bars.

from the middle pools in the experiment (level 2) were intermediate compared with those of larvae from the extremes of isolation but did not differ significantly from either level (level $1, P=.44$; level 3, $P=.06$; fig. 2).

\section{Discussion}

There was a positive relationship between isolation of experimental habitats and the foraging rates of dragonfly larvae that had colonized at each level. After a number of months in a common lab setting, larvae collected from the most isolated artificial pools in the experiment, $\sim 1 \mathrm{~km}$ from any source, consumed significantly more Daphnia than larvae collected from the pools that were closest to a potential source. Larvae from the most isolated pools had 1.5 times the foraging rate of larvae from the least isolated pools. Larvae from artificial pools at the experiment's intermediate level of isolation did not significantly differ from larvae drawn from more or less isolated pools. The foraging rates of these larvae were intermediate compared with those of larvae collected from more and less isolated pools, supporting the conclusion that colonist foraging rate and habitat isolation were positively related.

Three points strongly suggest that the observed differences were linked to the level of habitat isolation from which larvae were collected and were not the result of experiential differences between larvae. First, the use of artificial pools with identical initial conditions minimizes or eliminates the spatial autocorrelation in habitat condition typical of natural habitat patches. Second, we found no difference in prey availability in these artificial pools, in pool temperatures, or in larval body size at the time larvae were collected, indicating that larvae experienced similar conditions during the early larval period spent in the natal pool. Finally, larvae were held individually under common lab conditions for at least 5 months, approximately half of the larval stage. Even relatively minor differences in the early life conditions experienced by individuals can continue to have effects later in life (Broomhall 2004), and we cannot rule out the possibility that there may have been early induced effects from unmeasured conditions. However, the artificial mesocosm approach used here represents one of the best possibilities for eliminating spatial autocorrelation in local conditions across a landscape, and we did not detect differences in withinpool conditions across levels. Additionally, lab conditions were standardized and larvae were systematically distributed across shelves in the lab so that individuals from different pools and levels were thoroughly mixed, minimizing the potential for lab conditions to have systematic effects on differences between individuals from different pools and levels. Taken together, these results suggest that the differences we detected between individuals from different levels of isolation were intrinsic differences between larvae developing from eggs oviposited at different distances from source habitats, although the source of those intrinsic differences is unknown. Maternal effects or genetic differences between females with varying dispersal distances may be related to differences in their offspring, and further exploration of the factors underlying these differences would be profitable, probably providing insights into the development of phenotypic spatial structure.

Growing evidence from a range of taxa demonstrates that dispersers often differ phenotypically from individuals that do not disperse (Benard and McCauley 2008; Clobert et al. 2009) and that individuals with apparently similar capacities for dispersal may differ widely in how far they actually travel (Mabry and Stamps 2008). Behavioral, morphological, or physiological differences between dispersers and nondispersers suggest that the interactions between dispersers and residents in the newly colonized patch may be quantitatively or qualitatively different than expected based on average values of these traits taken from both dispersers and nondispersers. The consequences of this for the populations and communities in which dispersers settle has received less attention than the trait differences between dispersers and nondispersers despite their potential importance for population dynamics and community structure. Evidence based on population means that dispersers may contribute more or less than predicted to population demography and gene flow between patches has been found in some systems where it has been explored (Orell et al. 1999; Doligez and Pärt 2008), but there has been less work that examined the conse- 
quences of phenotype-dependent dispersal for interspecific interactions. However, Duckworth and Badyaev (2007) found that in western bluebirds (Sialia mexicana) a positive correlation between male aggressive behavior and dispersal propensity facilitated their displacement of a congener, the mountain bluebird Sialia currucoides, at their range margin. The displacement of mountain bluebirds by western bluebirds would not have been predicted by the levels of aggressiveness shown between mountain bluebirds and nondispersing western bluebirds (Duckworth 2006; Duckworth and Badyaev 2007). Our study suggests that differences can also arise in the offspring of individuals that differ not in whether their parents dispersed or remained at the natal site but in how far they traveled. Our data do not answer questions about phenotype-dependent dispersal itself. We do not know whether, or how, adult L. saturata breeding at experimental pools across varying levels of isolation differed from each other. Instead our data indicate that there is phenotypic variation among the offspring of dispersers across different levels of isolation that may determine the impact those individuals have within the colonized patch.

All individuals in this study were the offspring of adults that had dispersed away from their natal habitat and colonized a newly created pondlike habitat in the landscape. Offspring deposited relatively close to a source had lower foraging rates than those deposited far from any source, while individuals collected from pools that were intermediate to these two extremes also had foraging rates intermediate to larvae from close and far pools. Patterns in the magnitude of interspecific interaction coefficients may correlate with landscape structure being larger or smaller based on the level of habitat isolation. The temporal persistence of these effects is unknown. Trade-offs between traits correlated with dispersal and other traits determining fitness may lead to a shift in the population over time toward a phenotypic composition more similar to highly connected habitats (Hill et al. 1999b; Duckworth and Badyaev 2007). Nonetheless, in habitats such as temporary and semipermanent ponds where there are frequent temporal disturbances and high levels of local extinction (McCauley et al. 2008), these effects may affect the development of the recolonizing community.

Distance to different types of predator communities
(Storfer and Sih 1998) or levels of predation risk (Urban 2007) in natural populations of two Ambystoma salamander species have been found to be related to foraging rate. However, to our knowledge this is the first study to examine how isolation itself is related to the trophic behavior (i.e., foraging rate) of colonists arriving at habitat patches. Our finding that the dispersal distance traveled by parents and the foraging rate of their offspring are positively related suggests that correlations between dispersal behavior and other behaviors can have effects that propagate through multiple levels of the community in the receiving patch. Trophic cascades based on the identity of the top predator have received extensive attention in aquatic communities (Shurin et al. 2002 and references therein). Our results suggest that in temporally dynamic communities where recolonization following disturbance occurs frequently, both species sorting and phenotype sorting may occur across gradients of habitat isolation. One potential implication of this is that variation in dispersal distance correlated with differences in the competitive or predatory behavior of dispersers or their offspring may affect the ability of species to coexist in recolonized patches. This could generate community composition patterns that appear to be related to differences in dispersal behavior but are actually generated by spatial variation in the intensity of species interactions within the patch. Future work on phenotype-dependent dispersal should explore in more depth the carryover effects for colonized patches.

\section{Acknowledgments}

We thank the Napa County Land Trust and J. Callizo, C. Hill, and M. Hill for logistical support and access to the Wantrup Wildlife Sanctuary, where this work was conducted. A. Carleton and S. Schneider helped conduct fieldwork. This manuscript was improved by comments from two anonymous reviewers. S.J.M. was supported by a postdoctoral fellowship from the Center for Population Biology while conducting this research and by a Department of Ecology and Evolutionary Biology Postdoctoral Fellowship at the University of Toronto during the writing of this manuscript. T.B. was supported by a postdoctoral fellowship from FORMAS (Swedish Research Council for Environment, Agricultural Sciences, and Spatial Planning). 


\section{APPENDIX}

\section{Experimental Details}

\section{Spatial Context and Connectivity}

Only ponds on the Wantrup Wildlife Sanctuary (WWS) were included in the assessment of connectivity. Ponds off the reserve were excluded for two reasons. First, the ponds on the WWS included at least the three closest ponds for all of our experimental sites. Second, while we were able to verify that all ponds on the reserve had populations of Libellula saturata, ponds off the WWS either were cattle watering ponds or were located in wineries. These ponds typically have little to no emergent vegetation, experience large fluctuations in water levels across the season as they are used for irrigation, and have high levels of nutrient and chemical inputs that may make them less suitable for larval dragonflies. Nonetheless, if these are even weak source habitats for L. saturata, they would act to reinforce the isolation patterns of our experimental pools. The water bodies outside the WWS are strongly concentrated in the valley, where two of the WWS ponds, including our largest source lake, are also located, and pools up the slope of the WWS were farther from these water bodies.

The isolation index was slightly modified from Hanski (1999) as

$$
S_{i}=\sum_{j \neq i} \exp \left(-\alpha d_{i j}\right) C_{j}
$$

where $\alpha$ is a measure of the effect of distance on migration ( $1 / \alpha$ is the mean migration distance), $d_{i j}$ is the mean distance (edge to edge) between a source pond and the pools at a given level, and $C_{j}$ is the circumference of the source pond. Hanski's index of isolation was used because it integrates the potential contributions of multiple sources, lessening the extent to which we had to make assumptions about which sources were most important to the colonization of these pools.

Average dispersal distance is hard to estimate. The distribution is often skewed toward many individuals dispersing short distances, while a few individuals disperse over long distances. Moreover, as individuals search, they may be found long distances from the source population even though they may choose to settle and reproduce only a short distance away (Mabry and Stamps 2008). Here an average dispersal distance of $2 \mathrm{~km}(\alpha=0.5)$ still leads to separation between the nearest and farthest pool location, while an average dispersal distance of $1 \mathrm{~km}(\alpha=0.5)$ leads to probable separation between all three. In either case the rank order is maintained up to distances of $10 \mathrm{~km}$ (table A1).

\section{Pool Temperatures}

Thermometers recording maximum and minimum temperatures were placed in two randomly selected pools at each level on August 20, 2007, and temperatures were recorded on August 28, 2007. Two pools were again randomly selected at each level, thermometers were reset, and temperatures were recorded again on September 7, 2007.

\section{Predators}

The only potential predators of dragonfly larvae to colonize these pools were dytiscid beetles. These, however, were rare in the pools; a single adult was collected from one of the pools at the first level of isolation. Larvae from this pool did not differ in feeding rate from larvae collected in the other pools at this level (generalized linear model analysis: $\left.F_{2,45}=1.45, P=.247\right)$.

\section{Abundance of Other Odonates}

Peak abundances of dragonfly larvae collected from pools occurred at level 2 . There was a marginally significant effect of level on the abundance of Libellula sp. collected from pools (generalized linear model: $F_{2,14}=3.96, P=.051$ ), with a trend toward higher abundances at level 2 than at level 1 (Tukey's post hoc, $P=.058$ ). The other two comparisons were not significant (all $P>.1$ ). Combining all dragonfly larvae, there was a significant effect of level on abundance $\left(F_{2,14}=4.23, P=.043\right)$. The same trend was observed, higher abundances at level 2 than at level 1 $(P=.055)$, although in this contrast there was also a nonsignificant trend toward higher abundances at level 2 than at level $3(P=.094$; table A3).

Abundances of dragonfly larvae were not related to measures of behavior made on the dragonflies collected and brought into the lab. The abundance of Libellula collected from pools was not correlated with number of Daphnia eaten (Pearson's $r$ correlation $=0.493, N=12, P=$ .103 ) or the locomotor activity of larvae (Pearson's $r$ correlation $=0.237, N=12, P=.458$ ), nor were these behaviors correlated with the total abundance of dragonflies in pools (eaten: Pearson's $r$ correlation $=-0.462, N=$ 12 , $P=.131$; activity: Pearson's $r$ correlation $=0.076$, $N=12, P=.815)$.

Odonate richness was low in the tanks, and they were strongly dominated numerically by $L$. saturata colonists. Odonate richness in these tanks ranged between 1 and 3 species (means $\pm 1 \mathrm{SD}$ : level 1, $1.25 \pm 0.5$; level 2, $2.0 \pm 0.7$; level 3, $2.2 \pm 0.8$ ), but there was no difference in mean richness between levels (ANOVA, $F_{2,11}=2.15$, $P=.163)$. 
Table A1: Elevation of each set of pools and distances between sets of pools and ponds (Wantrup, Cabin, Valley, Upper, and Chiles) in the Wantrup Wildlife Sanctuary

\begin{tabular}{|c|c|c|c|c|c|c|c|c|c|}
\hline \multirow[b]{2}{*}{ Pool site } & \multirow{2}{*}{$\begin{array}{l}\text { Elevation } \\
\text { (m a.s.l.) }\end{array}$} & \multicolumn{5}{|c|}{ Distances $(\mathrm{km})$} & \multicolumn{3}{|c|}{ Isolation $\left(S_{i}\right)$} \\
\hline & & Wantrup & Cabin & Valley & Upper & Chiles & $\alpha=1$ & $\alpha=.5$ & $\alpha=.1$ \\
\hline 1 & 213 & .15 & .5 & .63 & 1.32 & 1.97 & 675 & 985 & 1,361 \\
\hline 2 & 255 & .40 & .41 & .69 & 1.13 & 1.73 & 731 & 1,014 & 1,366 \\
\hline 3 & 291 & .63 & .44 & .79 & 1.03 & 1.5 & 781 & 1,030 & 1,365 \\
\hline
\end{tabular}

Note: Distances to closest pond for each set of pools are in bold. Isolation for pools at each level is calculated by Hanski's (1999) isolation metric $S_{i}$, using $\alpha$ of $1,0.5$, and 0.1 , corresponding to average dispersal distances of 1,2 , and $10 \mathrm{~km}$.

Table A2: Mean abundance and standard error of potential prey in pools across levels collected in final time period

\begin{tabular}{lccc}
\hline Level & Baetidae & Chironomidae & Cuculidae \\
\hline 1 & 0 & $6 \pm 1.5$ & $10 \pm 8.7$ \\
2 & 0 & $21 \pm 6.9$ & $4 \pm .9$ \\
3 & $10 \pm 6.9$ & $14 \pm 2.8$ & $6 \pm 1.5$ \\
\hline
\end{tabular}

Table A3: Mean abundance and standard error of dragonfly larvae in pools across levels collected in final time period

\begin{tabular}{lcc}
\hline Level & All Libellula sp. & All dragonfly larvae \\
\hline 1 & $12.75 \pm 10.10$ & $15.75 \pm 10.77$ \\
2 & $129.8 \pm 46.28$ & $185.6 \pm 69.3$ \\
3 & $38.8 \pm 15.8$ & $44.8 \pm 13.68$ \\
\hline
\end{tabular}

\section{Literature Cited}

Barbraud, C., A. R. Johnson, and G. Bertault. 2003. Phenotypic correlates of post-fledging dispersal in a population of greater flamingos: the importance of body condition. Journal of Animal Ecology 72:246-257.

Benard, M. F., and S. J. McCauley. 2008. Integrating across life-history stages: consequences of natal habitat effects on dispersal. American Naturalist 171:553-567.

Benke, A. C., A. D. Huryn, L. A. Smock, and J. B. Wallace. 1999. Length-mass relationships for freshwater macroinvertebrates in North America with particular reference to the southeastern United States. Journal of the North American Benthological Society $18: 308-343$.

Broomhall, S. D. 2004. Egg temperature modifies predator avoidance and the effects of the insecticide endosulfan on tadpoles of an Australian frog. Journal of Applied Ecology 41:105-113.

Clobert, J., J.-F. Le Galliard, J. Cote, S. Meylan, and M. Massot. 2009. Informed dispersal, heterogeneity in animal dispersal syndromes and the dynamics of spatially structured populations. Ecology Letters 12:197-209.

Conrad, K. F., K. H. Willson, K. Whitfield, I. F. Harvey, C. J. Thomas, and C. J. Sherratt. 2002. Characteristics of dispersing Ischnura elegans and Coenagrion puella (Odonata): age, sex, size, morph and ectoparasitism. Ecography 25:439-445.

Cote, J., and J. Clobert. 2007. Social personalities influence natal dispersal in a lizard. Proceedings of the Royal Society B: Biological Sciences 274:383-390.
Crooks, K. R., and M. Sanjayan. 2006. Connectivity conservation. Cambridge University Press, Cambridge.

Dingemanse, N. J., C. Both, A. J. van Noordwijk, A. L. Rutten, and P. J. Drent. 2003. Natal dispersal and personalities in great tits (Parus major). Proceedings of the Royal Society B: Biological Sciences 270:741-747.

Doligez, B., and T. Pärt. 2008. Estimating fitness consequences of dispersal: a road to "know-where"? non-random dispersal and the underestimation of dispersers' fitness. Journal of Animal Ecology 77:1199-1211.

Duckworth, R. A. 2006. Behavioral correlations across breeding contexts provide a mechanism for a cost of aggression. Behavioral Ecology 17:1011-1019.

Duckworth, R. A., and A. V. Badyaev. 2007. Coupling of dispersal and aggression facilitates the rapid range expansion of a passerine bird. Proceedings of the National Academy of Sciences of the USA 104:15017-15022.

Hanski, I. 1999. Metapopulation ecology. Oxford Series in Ecology and Evolution. Oxford University Press, New York.

Hill, J. K., C. D. Thomas, and D. S. Blakeley. 1999a. Evolution of flight morphology in a butterfly that has recently expanded its geographic range. Oecologia (Berlin) 121:165-170.

Hill, J. K., C. D. Thomas, and O. T. Lewis. 1999b. Flight morphology in fragmented populations of a rare British butterfly, Hesperia comma. Biological Conservation 87:277-283.

Holyoak, M., M. A. Leibold, and R. D. Holt. 2005. Metacommunities: spatial dynamics and ecological communities. University of Chicago Press, Chicago. 
Ims, R. A., and D. O. Hjermann. 2001. Condition dependent dispersal. Pages 203-216 in J. Clobert, E. Danchin, A. A. Dhondt, and J. D. Nichols, eds. Dispersal. Oxford University Press, New York.

Mabry, K. E., and J. A. Stamps. 2008. Dispersing brush mice prefer habitat like home. Proceedings of the Royal Society B: Biological Sciences 275:543-548.

Massot, M., J. Clobert, P. Lorenzon, and J.-M. Rossi. 2002. Conditiondependent dispersal and ontogeny of the dispersal behaviour: an experimental approach. Journal of Animal Ecology 71:253-261.

McCauley, S. J., C. J. Davis, R. A. Relyea, K. L. Yurewicz, D. K. Skelly, and E. E. Werner. 2008. Metacommunity patterns in larval odonates. Oecologia (Berlin) 158:329-342.

McPeek, M. A. 1990. Determination of species composition in the Enallagma damselfly assemblages of permanent lakes. Ecology 71: 83-98.

Merritt, R. W., and K. W. Cummins. 1996. An introduction to the aquatic insects of North America. Kendall/Hunt, Dubuque, IA.
Needham, J. G., M. J. Westfall, and M. L. May. 2000. Dragonflies of North America. Scientific, Gainesville, FL

Orell, M., K. Lahti, K. Koivula, S. Rytkönen, and P. Welling. 1999. Immigration and gene flow in a northern willow tit (Parus montanus) population. Journal of Evolutionary Biology 12:283-295.

Shurin, J. B., E. T. Borer, E. W. Seabloom, K. Anderson, C. A. Blanchette, B. Broitman, S. D. Cooper, and B. S. Halpern. 2002. A cross-ecosystem comparison of the strength of trophic cascades. Ecology Letters 5:785-791.

Storfer, A., and A. Sih. 1998. Gene flow and ineffective antipredator behavior in a stream-breeding salamander. Evolution 52:558-565. Urban, M. C. 2007. Risky prey behavior evolves in risky habitats. Proceedings of the National Academy of Sciences of the USA 104: 14377-14382.
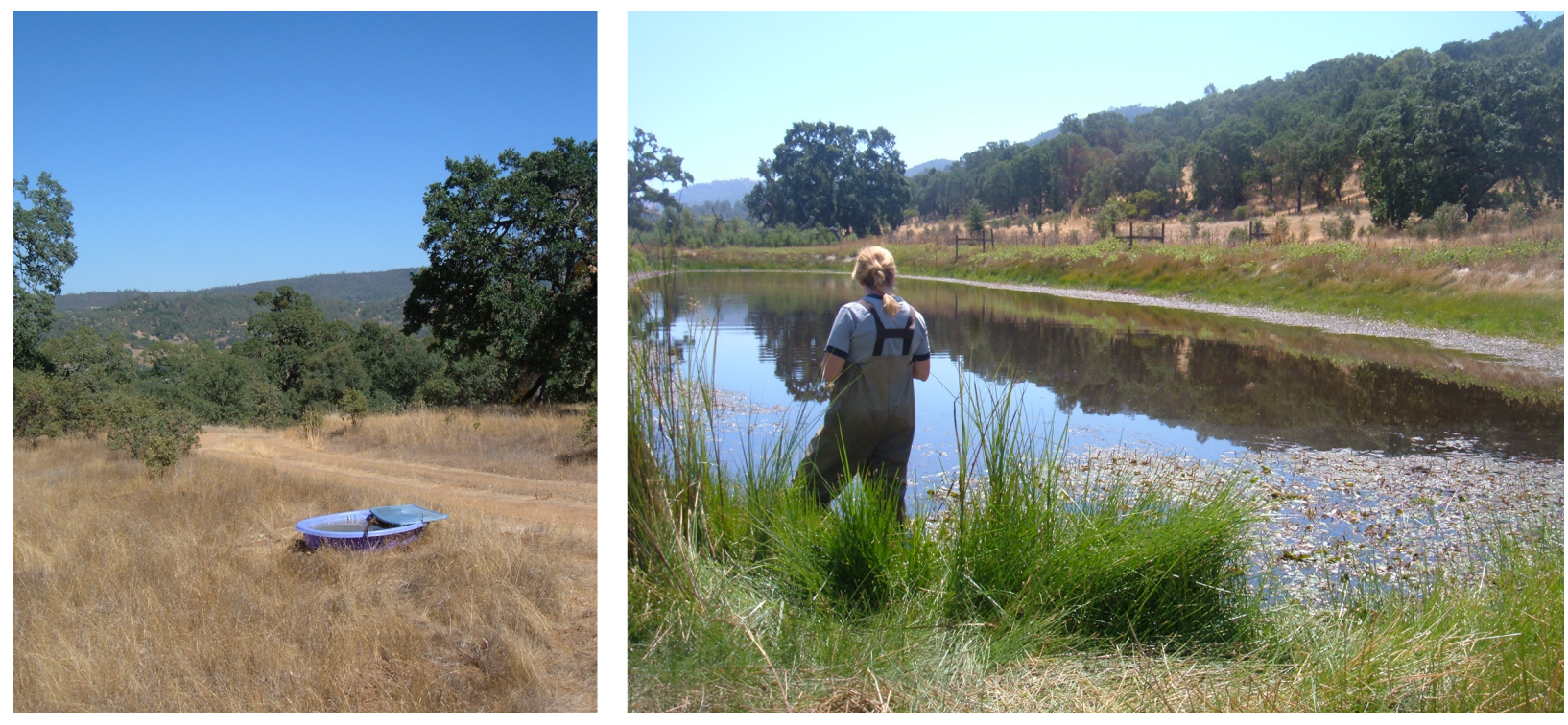

Left, experimental pool. Right, pond on the Wantrup Wildlife Sanctuary. Photographs by Shannon J. McCauley. 